\title{
New Theory on Foundation and Principle in Rural Anti-poverty
}

\author{
Xiaoxia Zhao \& Zhaoquan Fan \\ College of Humanities and Social Science, Sichuan Agricultural University \\ 46 Xin Kang Street, Ya'an 625014, Sichuan, China \\ Tel: 86-835-288-2345 E-mail: xiaoxzhao@sohu.com
}

Funding project: "social construction in new countryside and strategic research on escaping from poverty in a stable and complete way in rural areas of China (CR0616)" in Agricultural Development Research Center of Sichuan Province

\begin{abstract}
Anti-poverty is a common subject that all countries are facing with today. Amartya Sen defined it as a lack of capability instead of just a low income. According to his theory, combined with great changes in rural management structure since China implemented reform and opening-up policy, the thesis proposes a new concept of anti-poverty to develop communities' capability on the basis of rural communities. The break-ground activities of anti-poverty can begin with the rural communities on the principle of adhering to capability construction rather than material input with the fundamental purpose of developing community capability in rural areas. It is suitable to construct a multi-dimensional anti-poverty system taking governments as the leading part, villagers as the self-managers, and social institutions as the supporting parts and market as the adjustment mean. Thus, capability-oriented anti-poverty mechanism and the development road on inner resources can take shape in china's rural areas.
\end{abstract}

Keywords: Anti-poverty, Rural community, Capability construction, Development based on inner resources

Anti-poverty is a common subject that all countries are facing with today. There are different levels of poverty in both developed countries and developing countries. Examining the anti-poverty practice and experience, many governments and organizations have always adopted the accustomed and traditional way that emphasizes material inputs rather than capability construction to solve the problem, which is also called as "transfusion-oriented" anti-poverty. In 1998, Amartya Sen, the winner of Nobel Economic Prize, defined poverty as a lack of capability instead of a low income. With the help of his theory, this thesis proposes that rural anti-poverty in China has entered a new phase after 30 years since China implemented the reform and opening-up policy. To solve all difficulties in the rural anti-poverty, it is necessary to strengthen capability construction in rural communities and build capability-oriented anti-poverty mechanism.

\section{Anti-poverty Based on Rural Communities}

In fact, China began its reform from the rural areas 30 years ago. The rural reform started from the production group in People's communes to production villages in towns, and then to the self-employed in the household contract responsibility system. Agricultural tax is also changing from partial release to full release. In the process, fundamental management in rural areas has experienced great changes in both the form and the function. Nowadays, the villagers can manage affairs in the villages on their own. Such a structure replaces the People's communes, in which the relation between villages is the relation between guiding and being guided instead of that between superiors and subordinates. Villages and towns are fundamental institutions, while rural communities are the self-managed organization for villagers. The method by which farmlands distributed into villagers makes agricultural production change from production groups to families. Families replace production groups as the agricultural production units. Lives of villagers can be spread from families to villages and other more places, so the living function of villages can be more obvious and become the common link of communications among villagers.

In the past, villages functioned as the units for both agricultural production and villagers' lives. Now it only functions as the units for villagers' lives. The units for farmers' identities and activities are also changing gradually into communities. Villages and towns gradually change from the "production groups" in the past to rural communities. These communities 
establish the network of social management, public service and social support in rural areas, which play a practical role in the welfare, social aids, social charity, public security, family planning, the hygienic service, environmental protection, social dispute mediation, the life-support services, and so on.

Due to their importance, rural communities can be the beginning of rural anti-poverty. In fact, rural communities are both a small society and a large family. As a small society, anti-poverty can be carried out in those communities so as to overcome shortcomings in rural anti-poverty effectively, as a large family, anti-poverty carried out in rural communities can avoid difficulties in establishing capability-oriented anti-poverty mechanism. Compared with poor people in cities, social organizations for poor people in rural areas will become weaker as well as the basis of public service and resources offered to the society. Hence, anti-poverty in rural areas can emphasize both individuals and communities instead of individuals. It is urgent to form organization basis and social strength for anti-poverty. In a word, anti-poverty should base on rural communities, which can be regarded as the carrier. Anti-poverty in the whole communities can combine the targets for anti-poverty with the whole community, establish the whole functional system and community supporting network for anti-poverty, overcome shortcomings in individual anti-poverty, such as dispersivity, vulnerability, static condition and casualty, display such advantages as the whole with the intensive, integrity, power, systematic characteristics. In the phase of breaking ground, anti-poverty can only build the effective mechanism in the long term based on the rural communities and their functions in anti-poverty.

In fact, anti-poverty based on rural communities can not only definitely focus on all individuals to fight against poverty, who are the basis of anti-poverty, but also help to build the community supporting network and defense line for the efforts in anti-poverty, which is the guideline for anti-poverty. It doesn't imply the completeness, but means that it can provide the continuous resources from all walks of life for the rural anti-poverty, which is the social guarantee for rural people to completely get rid of poverty. Indeed, the continuous resources come from the capability of the rural community.

\section{Capability Construction in Rural Communities as the Main Principle}

Community capability is the combination of all the related capabilities in the community. Community capability in rural areas contains the following capabilities, such as the capability to enhance all people to be aware to take part in the management of community affairs, the capability to effectively formulate management system in rural communities, the capability to help villagers in trouble and alleviate villagers' difficulties and improve the development of rural communities, and the capability to communicate and exchange with institutions or organizations outside, and so on. All those capabilities can be divided into two aspects: individual faculty of villagers and organizing capability of communities. All the standards for these two aspects can be shown in the following table.

\section{Insert Table 1 About Here}

Awareness of villagers is the requirement for villagers' mental qualities in the capability construction of rural communities, including the awareness of law, the awareness of rights, the awareness of market and modern awareness, and so on. The awareness of law means that villagers should have basic knowledge of laws, should be willing to obey the principle of managing state affairs according to laws and to be good citizens who can observe laws and principles. The awareness of rights is that villagers should have the awareness to safeguard their own rights according to laws. The awareness of market requires villagers to obtain economic rules and regulations in the market, produce and live actively to adapt to the market and be rational citizens with the competitive and cooperative awareness. Modern awareness implies that villagers should get rid of all backward thoughts, advocate modern scientific civilization, display their creativity, seek for freedom and happiness and behave like villagers in the new century.

Villagers' qualities are the requirements for villagers' individual capabilities in the capability construction in rural communities, including morals, modern agricultural knowledge and technologies and competitive capability in markets, and so forth. First of all, villagers are required to become knowledge-oriented villagers with a good command of modern culture and knowledge, and to inherit the fine moral traditions of Chinese nation. Secondly, since modern agriculture needs villagers to have modern agricultural science and technologies, they should know how to carry out the scientific farming and strengthen agriculture through science and technology. Meanwhile, modern villagers should have the awareness of market, because agricultural industrialization requires markets both at home and abroad. Competitive capability is one basic quality villagers should obtain under the circumstance of globalization, and it can show villagers' economic capability well and guarantee the rise of villagers' income. Rural communities should organize local organizations or associations to establish all types of mutual economic cooperation organizations so as to enhance negotiation ability between villagers and markets as well as the ability against market risks, which is one effective measure to realize economic efficiency and profits in rural areas and is also the important manifestation of capability construction in rural communities.

Community activity refers to the capability of communities to participate in social activities as a social role including alleviating villagers' difficulties, coping with emergencies and conflicts, reassigning resources and organizing villagers 
to take part in community affairs, and so on. In a word, it means the capability of communities to cope with all related affairs in the community. It has played an important role in the capability construction.

In fact, rural communities are becoming the network of social management, public service and social support in rural areas now. They play more and more active roles in many aspects of rural lives, including welfare, social aid, social charity, public security, family planning, the hygienic service, the judicature rectifies, the environmental protection, the social dispute mediation, the life-support services, and so on. Hence, the community activity is closely related with the stability of rural society and living quality of villagers. It is important and crucial to strengthen activity construction in rural communities under the circumstance of poor basis in rural community construction and low-level of villagers' qualities.

Capability of communities to meet with villagers' needs refers to the supply capability to meet with villagers' material and cultural needs. Community construction takes it as the objective to meet with villagers' needs, which are also the starting point and foothold for the community construction. If a community can provide good infrastructure like shopping, education, sanitation and entertainment, and high-quality public services like social aids for villagers, it has a high-level capability to meet with material and cultural need of villagers. At present, social safeguard system is still not so perfect; the hygienic infrastructure is of low level, so that villagers can't solve a series of problems, like the aging problem and the difficult-for-seeing-a-doctor problem, and so on. Besides these, there are other difficulties in villagers' families, for instance, some villagers go out to work in outside areas and earn money to support the family, so their families confront with the difficulties to take care of old people, the youth and women. Imbalance of rural educational resources prompts rural teenagers to flood into the cities and thus exerts pressure on urban educational resources, which reflects rural teenages' desire for education equity. The problem of "prostitution, gambling, drugs" is due to the backwardness of cultural construction in rural communities, and the unsatisfied cultural demand of citizens in rural communities. Therefore, improving the community capability to satisfy the citizens' need is an important index of the communities' capability construction.

Diplomatic capability of community. It refers to that community creates a more comfortable external living environment, abundant social resources and public trust for citizens through diplomacy and efforts. Diplomatic capability of community creates a better social support network for community citizens. Communities establish the extensive diplomatic relations through diplomacy with external organizations and individuals and provide social support for citizens to participate in social activities and utilize social resources. A community with good diplomatic capability is able to bring about more social resources and better external living environment for its citizens, make its citizens live in harmony with citizens of other communities, and fulfill the social mobility in a better way.

Rural anti-poverty should develop communities' capability, that is, aid-target's ability, especially community's capability should be developed at the key stage of anti-poverty. Developing capability should be a direct objective and important task of anti-poverty project. Rural community's capability is the guarantee of the solution to the poverty problem in rural areas and also the "source of strength" in the anti-poverty project. The long-term goal of poverty alleviation programme is developing community's capability of poverty-stricken areas.

Rural anti-poverty should develop communities' capability. With the guidance of this idea, developing communities' capability should be the core of anti-poverty programmes in China at the key stage. An multi-dimensional anti-poverty system led by government, self-managed by villagers, supported by social institutions and adjusted by market, and capability-oriented anti-poverty mechanism should be established. The research shows that the key to establish the capability-oriented anti-poverty mechanism is the innovation of anti-poverty mechanism. The innovation of anti-poverty mechanism demands the introduction of new theories, methods and working skills to rural community construction. The working staff should engage in the rural community construction as several roles such as a social broker, mediator, social controller and educator. With the idea of helping people and helping themselves, villagers should be encouraged self-determination, to organize and coordinate the social resources of governmental and non-governmental organizations, to mobilize social capital, technology, information in order to remedy the inconvenience of government and the unsoundness of market. The mechanism led by government, self-managed by villages and supported by social institutions should be established to develop community's capability in a way of inner resources. Then how to develop rural community's capability?

First, human resource input and development in rural areas should be paid attention to. Through involvement, participation, interaction, exchange, negotiation, villagers' diligence, self-help and cooperation can be cultivated, the idea of self-empowerment and self-consciousness can be reinforced as well. Through cultural activities and training, villagers' quality and competence can be enhanced. Developing community's capability must be based on this.

Second, self-management mechanism in rural communities' should be innovated. Villager's self-development, self-administration and self-service should be reinforced; the development of various social groups, associations, mutual economic aid organizations, and other social service institutions should be supported; community villagers should be well organized; supply system of rural public products and public service function should be reconstructed, social 
security and service system in rural communities should be established; involvement of various social service organizations including NGO and NPO in rural community construction should be positively supported; rural community's administrative system with high efficency and low cost should be built, which lays system and material foundation for rural community construction.

Third, specialization level of talents of rural management and service should be promoted. Specialized and professional staff of community management and service is the talent guarantee of resolving contradictions, eaving the situation and satisfying the needs of people who are in need of help.

\section{The Anti-Poverty Concept of Unity of Substance and Function}

Rural anti-poverty project should develop communities capability on the basis of rural communities. Based on the rural communities, it not only helps poverty-stricken individuals eradicate poverty but also accumulates the joints efforts of anti-poverty on the community scale. The research discovers that the final solution to poverty problem largely depends on the capability enhancement of poverty-stricken individuals and the thorough eradication of poverty also depends on the capability enhancement of communities the poor individuals belong to. The weakness of agricultural base, dispersion of rural communities and fragility of individual farmers' ability determines that anti-poverty project should not only focus on the ability enhancement of poor individuals but also organize the farmers to enhance rural ability. Anti-poverty project should adhere to the principle of "Unity of Substance and Function"

"Migrant workers" is related to poverty problem in rural China. As is well known, migrant workers has become a sign of Chinese reform with Chinese characteristics in the past thirty years. The data shows that the number of migrant workers has reached 120 million, which are composed of two generations. It is acknowledged that migrant workers are the result of farmers' emancipation from agriculture due to rural reform in China. Migrant workers have become one active force in the rural reform and have also played a great role in bringing urban economic prosperity, promoting rural economic growth and renewing ideas in rural areas. Meanwhile, migrant workers' qualities have been enhanced in the migrant work. However, the research indicates that poverty problem has not been solved with the enhancement of migrant worker's qualities and material input returning to rural areas. By contrast, issues of agriculture, farmer and rural area have escalated into issues of agriculture, farmer, rural area and migrant workers. The problem of migrant workers has become an important element of poverty-returning, which refers to returning to poverty after poverty eradication. What is the reason for emergence of migrant worker problem? Seemingly, migrant work of farmers has led to rural emptiness of farmers and the problem of stay-at-home children and elders, which aggravates rural poverty and induces returning to poverty. In fact, migrant work of farmers itself is not a problem. The problems concerning migrant workers are caused by that some related issues haven't been properly solved. The inner reason for migrant worker problem lies in the situation in rural and urban areas, unsoundness of social mobility system and system barrier of social policies, as well as a function of rural communities and low ability of farmers. This thesis doesn't deal with the aspects of social mobility system and social policies.

The problem of migrant workers is related to problem of labor-export areas as well as problem of labor-import areas. As for the labor-export areas, the major problem is the problem of stay-at-home children and elders. Farmers go out of the countryside to seek wealth, leaving their families in the hometown. The family members, including women, children and elders, which is called as "386199 phenomenon" in academic field, stay at home. The problem of "stay at home" itself is not a problem. The problem is caused by that rural communities haven't satisfy the needs of stay-at-home families, which results in the problems of stay-at-home children, elders and women. Surveys show that many problems related to stay-at-home families are due to non-feasance of rural communities and inability of stay-at-home families. In rural communities, no mechanism or community force attend stay-at-home families. Although some needy stay-at-home families can benefit from social welfare such as lowest subsistence allowances, they must depend on themselves to rescue themselves. If they fail to rescure themselves, stay-at-home families might fall into poverty or return into poverty. Surveys also show that some organizations of NGO, NPO implement poverty alleviation aid projects and environment-friendly poverty alleviation projects in Sichuan, Yunnan, Guizhou, Gansu, Inner Mongolia, which organize community villagers to develop group capabilities, focusing on cultivating community capability and developing farmers' capabilities. This turns out to be economic profits and social benefits. Scrutinizing the anti-poverty modes of $\mathrm{NGO}$, it can be concluded that anti-poverty programmes implemented by NGO usually focus on developing group capabilities of communities instead of individual capabilities.

Anti-poverty mode of international organizations of NGO - develop community's capabilities rather than material input - has given us valuable enlightenment. Supposing a rural community with good capabilities to take action, satisfy villagers' needs and diplomatize is able to provide better service for stay-at-home families, stay-at-home related problems will decrease considerably and thus secondary poverty and poverty-returning will decrease. If a rural community is able to undertake the social service shifting from government, social public service in rural areas will be provided in a better way. Thus, anti-poverty project should be guided by the concept of unity of substance and function, that is, the break-ground activities of anti-poverty can begin with the rural community on the principle of adhering to 
capability construction rather than material input with the fundamental purpose of developing community capability in rural areas. Capability-oriented anti-poverty mechanism and the development road on inner resources can take shape in China's countryside, which will open a new prospect for anti-poverty in rural areas after initiation of reform and opening-up for 30 years.

\section{References}

Amartya, Sen. (2001). Poverty and Famines. Beijing: Commercial Press.

Duan, Shijiang \& Shi, Chunling. (2004). Anti-poverty in Rural China: Strategy Evaluation and Perspective Choice. Journal of Hebei University (Philosophy and Social Science), 4, (6), 76-79.

Gan, Xinkui. (2007). Current Conditions and Route Choice of New Rural Community Construction. Theory Journal, (1), 57-59.

Hu, Hongshu. (2007). Villagers' Self-governance and Public Choice in Rural Community -Decision-making Mechanism of Supply of Rural Public Products. Public Finance Research, (2), 38-40.

Qian, Ning. (2007). A Study of the New Poverty in the Rural Development and the Construction of Community Capacity from the Perspective of Social Work. Thinking, (1), 33.

Theodore W. Schultz. (1998). The Economics of Being Poor - Lectures of Nobel Economic Science Prize Winners. Shanghai: Shanghai People's Publishing House.

Wang, Dachao. (2004). Research on Anti-poverty in Urban and Rural Areas in China in Transitional Period. Beijing: People's Publishing House.

Wu, Jianzhi. (2006). Role of Non-governmental Organizations in Rural Community Construction. Forward Position, (12), 210-212.

Xu, Yuanyuan. (2006). Rural Economy Government's Responsibility in Rural China Anti-poverty. Rural Economy, (3), 74-77.

Zhang, Yaojie. (2007). The Change of the Mode of the Rural Community Governance. Lanzhou Academic Journal, (1), 57-59.

Zhao, Junchao. (2005). Theory and Practice on Poverty Relief and Development. Beijing: China Financial \& Economic Publishing House.

Table 1. Rural community capability and social functions

\begin{tabular}{|c|c|c|c|}
\hline Target names & Nature & Contents & Symbols \\
\hline $\begin{array}{l}\text { Awareness of } \\
\text { villagers }\end{array}$ & \multirow{2}{*}{ Individual } & $\begin{array}{l}\text { Mental qualities including awareness of law, awareness of } \\
\text { rights, awareness of market and modern awareness }\end{array}$ & $\mathrm{X}_{\text {Awareness of villagers }}$ \\
\hline $\begin{array}{l}\text { Qualities } \\
\text { villagers }\end{array}$ & & $\begin{array}{l}\text { Individual capabilities including morals, modern agricultural } \\
\text { knowledge and technologies and competitive capability in } \\
\text { markets }\end{array}$ & $X_{\text {Qualities of villagers }}$ \\
\hline $\begin{array}{l}\text { Activity } \\
\text { community }\end{array}$ & \multirow{3}{*}{$\begin{array}{l}\text { Organizing } \\
\text { capability } \\
\text { of } \\
\text { community }\end{array}$} & $\begin{array}{l}\text { Capability to participate in social activities as a social role } \\
\text { including alleviating difficulties, coping with emergencies and } \\
\text { conflicts, reassigning resources and organizing villagers to } \\
\text { take part in community affairs }\end{array}$ & $\mathrm{X}_{\text {Activity of community }}$ \\
\hline $\begin{array}{l}\text { Community } \\
\text { capability to meet } \\
\text { with villagers' } \\
\text { needs }\end{array}$ & & $\begin{array}{l}\text { Supply capability to meet with villagers' material and cultural } \\
\text { needs }\end{array}$ & $\begin{array}{l}\text { X Community capability } \\
\text { to meet with villagers' } \\
\text { needs }\end{array}$ \\
\hline $\begin{array}{l}\text { Capability to deal } \\
\text { with affairs with } \\
\text { outside world }\end{array}$ & & $\begin{array}{l}\text { Capability to provide a comfortable living surroundings and } \\
\text { enough social resources for villagers with the efforts in } \\
\text { communication with the outside world }\end{array}$ & $\begin{array}{l}\mathrm{X} \text { Capability to deal with } \\
\text { affairs with outside world }\end{array}$ \\
\hline Social function & \multicolumn{3}{|c|}{$\begin{array}{l}Y=f\left(X_{\text {Awareness of villagers }}, X_{\text {Qualities of villagers }}, X_{\text {Activity of community }}, X_{\text {Community capability to meet with villagers' needs, }} \text {, }\right. \\
\left.X_{\text {Capability to deal with affairs with outside world }}\right)\end{array}$} \\
\hline
\end{tabular}

